\title{
ОПЫТ БОРЬБЫ С ЭПИДЕМИЯМИ В ЕНИСЕЙСКОЙ ГУБЕРНИИ В ПЕРВЫЕ ГОДЫ СОВЕТСКОЙ ВЛАСТИ
}

\section{EXPERIENCE IN COMBATING EPIDEMICS IN THE YENISEI PROVINCE IN THE EARLY YEARS OF SOVIET POWER}

\section{Krylov \\ O. Alekseev}

Summary: The article is devoted to the experience of the struggle of the Soviet health authorities with epidemiological diseases in the first years of Soviet power, on the example of the Yenisei province. The article deals with the problems of the formation of organizational structures of Soviet medicine, touches on the specifics of creating a sanitary and antiepidemic organization in the difficult conditions of the 1920s. Archival materials allow you to get an idea of the measures that were taken to combat the epidemics of typhus, cholera, and malaria, and make it possible to track the dynamics of the spread of epidemics in the province. The documents of the 1920 s reflect the problem of medical personnel, the lack of premises for infectious hospitals, the availability of medicines, and the specifics of sanitary and educational activities in the Yenisei province.

Keywords: Yenisei province, Krasnoyarsk, Gubzdrav, Soviet health care, epidemics, sanitary and educational activities.
Крылов Игорь Иванович

К.и.н., дочент, Красноярский государственный аграрный университет

krilov24@yandex.ru

Алексеев Олег Геннадьевич

К.и.н., доцент, Сибирский федеральный университет (Красноярск)

fukidid2007@yandex.ru

Аннотация: Статья посвящена опыту борьбы органов советского здравоохранения с эпидемиологическими заболеваниями в первые годы советской власти, на примере Енисейской губернии. В статье рассматриваются проблемы формирования организационных структур советской медицины, затрагивается специфика создания санитарно-противоэпидемической организации в сложных условиях 1920-х годов. Архивные материалы позволяют получить представления, о мерах, которые предпринимались для борьбы с эпидемиями тифа, холеры, малярии, дают возможность в динамике проследить распространения эпидемий по территории губернии. В документах 1920-х годов находит отражение проблема медицинских кадров, отсутствие помещений для заразных больниц, обеспеченность медикаментами, затрагивается специфика санитарно-просветительской деятельности в Енисейской губернии.

Ключевые слова: Енисейская губерния, Красноярск, Губздрав, советское здравоохранение, эпидемии, санитарно-просветительская деятельность.

В сентябре 1919 года был сформирован Сибирский революционный комитет и при нем в 1920 г. был организован и начал работу Отдел здравоохранения Сибревкома. В функции отдела входило координирование деятельности чрезвычайных комиссий по борьбе с эпидемиями, решение вопроса о распределение врачей и средних медработников, снабжение медицинскими препаратами и оборудованием регионов Сибири. Широкий фронт работ по строительству советской системы здравоохранения поставил перед отделом практически не выполнимую задачу, в итоге в 1920 г. была создана новая структура в основу которой был положен принцип объединения всего медицинского дела в Сибири в единую организацию, возглавляемую Сибздравом, для решения медицинских проблем на местах были организованы губернские и уездные отделы здравоохранения [16, с. 215216].

В январе 1920 года, в Енисейской губернии, начал формироваться губернский отдел народного здравоохранения (Губздрав). Организация Губздрава проходила в тяжелой эпидемиологической обстановке, Енисейскую губернию захлестнули эпидемии сыпного и возвратного тифов, достигших в 1920 году громадных размеров, больницы, лазареты и бараки были переполнены боль- 
ными. Сложная эпидемиологическая ситуация усугублялась хозяйственной разрухой и антисанитарией, недостатком медицинского персонала, мобилизованного военным ведомством, нехваткой топлива, медикаментов, перевязочного материала, отсутствием связи между центром и уездами. Продвижение армии Колчака и волна беженцев создали благоприятные условия для распространения эпидемии тифа.

Для борьбы с тифом, в начале 1920 г., создавались Чрезвычайные комиссии (Чекатиф). В Красноярске такая комиссия была создана в феврале 1920 г. Данная комиссия объединяла гражданские, военные и железнодорожные ведомства для борьбы с эпидемиями. Созданные Чекатифы развертывали в городах и селах инфекционные больницы [17, с. 19]. На железнодорожных станциях открывались изоляционно-пропускные пункты. Для выявления и госпитализации больных и подозрительных, создавались санитарные отряды и дружины.

Созданному Енисейскому губернскому отделу народного здравоохранения приходилось работать на нескольких направлениях сразу, производить работу по открытию построенных врачебных пунктов, создавать временные изоляторы для инфекционных больных, принимать экстренные мероприятия по борьбе со вспыхнувшей по уезду эпидемией тифа. В связи с этим Губздрав завершил свое окончательное формирование и начал полноценно функционировать только к 1 мая 1920 г. В феврале 1920 г., был окончательно сформирован санитарно-эпидемический подотдел, в основу деятельности которого была положена организация санитарного надзора в Енисейской губернии, наблюдение за санитарным состоянием населенных пунктов и предприятий, проведение противоэпидемических и профилактических мероприятий, значительное внимание уделялось санитарно-просветительской деятельности $[1$, л. 1, 45]

Архивные материалы не позволяют в полной мере составить целостную картину распространения эпидемии тифа за 1920-й г. по населенным пунктам Ени- сейской губернии. Причиной неполноты сведений, зарегистрированных больных, являлся низкий уровень статистических данных, которые поступали в Красноярск, от главврачей госпиталей, больниц и участковых врачей. Сложно сказать насколько поступавшие сведения полноценно отражали реальную ситуацию с распространением эпидемии. Данные о заболевших поступали не своевременно в виду отсутствия качественной телеграфной связи с центром, врачи, загруженные работой на местах, не всегда имели возможность регулярно отчитываться о количестве заболевших, при этом значительная часть населения, проживающего на частных квартирах не обращалась в больницы и не подлежала медицинскому учету. Из полученных данных можно проследить лишь ход эпидемии по числу зарегистрированных больных с февраля по август 1920 г., данные таблицы 1.

Огромное число больных сыпным возвратным и брюшным тифом и отсутствие мест в заразных больницах, поставило перед санитарно-эпидемическим подотделом первоочередную задачу перепрофилировать все имеющиеся в городе Красноярске больницы в заразные, дополнительно были открыты две больницы для заразных больных в бывшем архиерейском и ночлежном домах. К концу февраля 1920 г. на город приходилось 880 госпитальных мест на 2 тысячи зараженных тифом, что привело к перегруженности больниц, пациенты вынуждены были ждать по нескольку дней в очереди, чтобы попасть на больничную койку. По всей Енисейской губернии к 1 октября 1920 г. было открыто 70 заразных бараков вместимостью до 700 мест [1, л. 4].

Существенным препятствием, не позволявшим открыть достаточное количество инфекционных больниц, являлось отсутствие подходящих под медицинские нужды зданий и помещений, в большинстве случаев лечебные учреждения размещались в зданиях, требующих ремонта. Повсеместно встречалась скученность среди пациентов, в результате больные разными видами тифа попадали в общие госпиталя, что приводило к последо-

Таблица 1

Сведения о зарегистрированных больных, тифом, по городу Красноярску и уездам Енисейской губернии с февраля по август 1920 г. [составлено по: 12, с. 183-187], [2, л. 81]

\begin{tabular}{|c|c|c|c|c|c|c|c|}
\hline & февраль & март & апрель & май & июнь & июль & август \\
\hline г. Красноярск & 9003 & 13584 & 8560 & 3993 & 2084 & 1103 & 521 \\
\hline Красноярский уезд & - & 3240 & 1011 & 450 & 531 & 484 & 156 \\
\hline Минусинский уезд & - & - & 1643 & 744 & 556 & 706 & 366 \\
\hline Канский уезд & 7581 & - & - & 2093 & 3094 & 1406 & 527 \\
\hline Ачинский уезд & 2373 & 4592 & 4383 & - & 975 & - & - \\
\hline Енисейский уезд & - & - & - & - & 364 & 262 & 163 \\
\hline
\end{tabular}


вательному заражению сначала одним, а потом другим видом тифа и только с ослаблением эпидемии удалось разделить больных сыпным и возвратным тифом [1, л. 39.].

Значительная часть заболевших лежала на дому в тяжелых санитарных условиях. Для обеспечения данных больных город Красноярск был разбит первоначально на 30 врачебных участков, а потом, из-за недостатка медицинских работников, произошло укрупнение до 16. Персонал участка комплектовался врачом, фельдшером и сестрой милосердия, на которых возлагалось оказание медицинской помощи на дому и наблюдение за санитарным состоянием своего участка. Обычной практикой в данное время являлись дежурства сестер и сиделок в домах тяжелобольных [1, л. 21].

Дополнительным фактором, ограничивающим борьбу с эпидемиями, были сложные условия, при которых приходилось работать медицинскому и санитарному персоналу. Постоянные контакты с больными приводили к массовой заболеваемости среди работников здравоохранения, только за 1920 год тифом переболело 109 врачей, 172 фельдшера и лекарских помощника, 99 сестер милосердия и 708 прочих сотрудников. При этом наблюдалась высокая смертность как у врачей, так и у младшего медицинского персонала, от тифа умер 21 врач, 10 лекпомов и фельдшеров, 5 медицинских сестер и 39 санитаров. Самое большое число заболевших и умерших наблюдалось среди младшего медицинского персонала, поскольку именно они все время находились рядом с заболевшими, так, например, 2-3 санитара постоянно дежурили в палате на 60 пациентов [5, с. 187].

Высокая заболеваемость и смертность привели к серьезной нехватке врачей, в результате наблюдалась постоянная перегруженность медицинских работников, так в Красноярске один врач обслуживал 3775 человек, в то время как в среднем по губернии - 16106 человек. Распространение эпидемии с каждым днем требовало все большего числа медицинских работников, между тем Енисейский губернский отдел здравоохранения был неспособен решить данную проблему. При этом медицинский персонал неравномерно распределялся по губернии, значительная часть врачей работала в городах, так из 85 врачей Енисейской губернии 28 работали в губернском города Красноярске, а остальные 57 были распределены по уездам губернии. [13, с.42].

Под руководством санитарно-эпидемического подотдела формируется Красноярский дезинфекционный отряд, подобные отряды и санитарные дружины формировались во всех уездах губернии, где эпидемия тифа охватывала целые селения. В функции отрядов входила организация заразных бараков, большинство из которых обеспечивались дезинсекционными камерами или жаровыми камерами-банями, проведение противоэпидемических мероприятий направленных на выявление заразных больных и их последующую госпитализацию $[1$, л. 4].

Гражданская война поставила перед медиками Енисейской губернии еще одну задачу борьбы с эпидемией азиатской холеры. Можно выделить основных распространителей болезни, беженцы из голодных губерний Европейской России, поскольку неурожай в Поволжье и в других районах страны привел к массовому притоку переселенцев, которые устремились по Транссибирской железной дороге на восток. Так же причинами распространения заболевания были частные лица и организации, приезжающие за хлебом, и заражение источников питьевой воды.

Эпидемия азиатской холеры в Енисейской губернии получила малое распространение, так как в тех районах Сибири, где холера свирепствовала, а это Омск, Томск, Челябинск, местные власти запрещали въезд и выезд, что заметно облегчало борьбу с инфекционным заболеванием. Противоэпидемическая обсервация пассажиропотока на транспорте, временное перекрытие больших трактов давала положительный результат [11, с. 93].

По сообщениям Губздрава холера в Енисейской губернии получила наибольшее распространение в 1921 году. Первые заболевания имели место в Ачинске, потому что инфекция шла с запада, после чего холера начала распространятся в Ачинском, Канском, Красноярском, Енисейском уездах. Эпидемия в 1921 году застала Енисейскую губернию не подготовленной. По статистическим данным на 1921 г. насчитывалось 538 случаев холеры, а в 1922 г. всего 81, из которых 29 приходилось на города и 52 на сельскую местность [14].

Губздрав в срочном порядке организует холерные бараки, отдает распоряжения о предоставлении помещений под остановочные пункты для переселенцев на станции Красноярск, Ачинск, Канск, а также вблизи пароходных пристаней [4, л. 11].

Одной из приоритетных проблем, стоящих перед советскими органами, являлось обеспечение населения губернии чистой водой. Централизованный водопровод был только в губернском городе Красноярске, обеспечение питьевой водой в уездных городах было неудовлетворительное. Так, на юге губернии, в городе Минусинске оказалась годной к употреблению лишь ключевая вода. Подобная ситуация наблюдалась и в Ачинском уезде. Отсутствие или ненадлежащее качество колодцев приводило к тому, что местное население использовало воду из открытых водоемов, для водопоя, купания и стирки белья. При этом повсеместно реки использовались для вывоза нечистот и навоза [10, с. 24]. 
Для обеспечения населения чистой водой, в ряде мест общего пользования устанавливались кипятильники и баки с кипяченой водой. Обследовались источники водоснабжения. Часть водопроводных будок и дворов, в городе Красноярске, в которых находились колодцы, были приведены в санитарное состояние. Отводились специальные места для сброса отходов и стирки белья. В пределах города Красноярска была произведена очистка берегов рек Качи и Енисея, от навоза и мусора, путем засыпки толстым слоем земли. Был организован строгий санитарный надзор за прибывающим в город населением из зараженных районов. Открывались холерные бараки и проводились обязательные противохолерные прививки [9, с. 161].

Подобные мероприятия были намечены и для уездов, но выполнение данных работ затруднял целый ряд факторов, таких как недостаток материальных средств, малочисленность штата медработников, большие расстояние от врачебных пунктов [1, л. 12-13].

В уездах организация борьбы с заразными заболеваниями проводилась прежде всего через участковый медицинский персонал, который в переделах своего участка проводил санитарную разведку, регистрацию заразных больных, дезинфекцию зараженных помещений [1, л. 46]. В сельские населенные пункты, где были обнаружены признаки холеры, командировали отряды врачей, в обязанности которых входило проведение противохолерных прививок, а жителям населенных пунктов, где выявлялись очаги эпидемии, запрещалось покидать пределы своего участка [7, л. 8.].

Предпринятые чрезвычайные меры и самоотверженная работа врачей способствовали резкому снижению эпидемической заболеваемости тифом, что послужило основанием ликвидации чрезвычайной комиссии, а также уездных органов по борьбе с тифом. Согласно приказу, Енисейского Губисполкома, от 24 мая 1922 г., все противоэпидемические функции передавались здравотделам [3, л. 35].

В ходе напряженного труда медицинских работников, при помощи советских организаций и населения, удалось значительно снизить эпидемию холеры к концу 1922 г. В 1923 г. на всей территории Сибири не было зарегистрировано ни одного случая заболевания азиатской холерой [16, с. 237].
В 1922 году в губернии началась эпидемия малярии, которая распространялась в основном на юге Енисейской губернии, так как здесь существовали благоприятные климатические условия, сильная заболоченность территории, слабо развита медицинская сеть, особенно на селе. Как итог на конец 1923 г. было зарегистрировано 44000 больных малярией.

Для борьбы с малярией санитарно-эпидемическим подотделом Губздрава организовывались специальные межведомственные комиссии, главной противомалярийной мерой была признана хинизация населения. Дополнительно был разработан план санитарных гидротехнических работ по осушке заболоченных местностей и улучшения водоснабжения населенных пунктов [5, л. 12].

Стали создаваться специальные учреждения - малярийные станции. Созданная 24 апреля 1924 г., Красноярская малярийная станция помещалась в здании медико-диагностической лаборатории и работала в общегубернском масштабе. Эта станция насчитывала штат из двух врачей, фельдшера, сестры милосердия и состояла из трех отделов [5, л. 122.].

Первый отдел - амбулатория. Средняя пропускаемость амбулатории в 1924-1925 гг. составляла 90 человек в день. Амбулатория брала кровь у больных малярией, занималась непосредственным лечением маляриков. В функции этого отдела малярийной станции входило обследование жилищ на выявление зимующих форм комара, обеспечение больных лекарствами. Следующим отделом малярийной станции являлась лаборатория. Она проводила исследование крови. Последний отдел - стационар. Стационар находился в ведении терапевтического отдела губернской больницы. С уездами малярийной станцией была налажена связь через регистрацию больных малярией. С начала апреля 1925 года станцией были организованы курсы по подготовке персонала для подвижных малярийных станций, которые направлялись в уезды. Меры по борьбе с малярией заключались в снабжении медицинских учреждений хинином [6, л. 3435]. Лишь к 1927 г. удалось добиться значительного снижения данного инфекционного заболевания.

Материалы государственного архива позволяют проследить динамику распространения эпидемий по городам и сельской местности Енисейской губернии, во вто-

Таблица 2

Развитие заразных заболеваний по Енисейской губернии за 1922-1923 гг.

[составлено по: 5, Л. 121 об.].

\begin{tabular}{|c|c|c|c|c|c|c|}
\hline & сыпной тиф & возвратный тиф & брюшной тиф & малярия & оспа & холера \\
\hline 1922 г. & 17683 & 13467 & 4963 & 9842 & 2782 & 81 \\
\hline 1923 г. & 5985 & 4517 & 2578 & 43067 & 1744 & - \\
\hline
\end{tabular}


рой половине 1920-х годов.

Анализируя эпидемиологическую обстановку в регионе можно отметить высокий уровень распространения инфекционных болезней, на всем протяжении 1920-х годов. Этому способствовали географические и климатические условия, слабая техническая оснащенность специальных учреждений, а также неспособность решить одну из главных проблем, недостаточное количество квалифицированных специалистов. Так, в течение второй половины 1920-х годов, вследствие плохого водоснабжения и антигигиенических условий жизни большинства населения губернии заболеваемость малярией и брюшным тифом продолжала оставаться на довольно высоком уровне. При этом постепенное восстановление народного хозяйства, а также комплексные мероприятия, предпринимаемые административными органами по предупреждению эпидемий, такие как госпитализация больных и подозреваемых, санитарная обработка и прививочная компания, привели к значительному снижению уровня заболеваемости населения по сравнению с началом исследуемого периода.

Огромное значение в развитии здравоохранения сыграл III съезд здравотделов Сибири. Съезд обсудил важнейшие вопросы строительства советского здравоохранения. Особое внимание было уделено вопросу о единстве советской медицины, профилактическому направлению и диспансеризации, улучшению медицинской помощи в количественном и качественном отношении. Съезд призвал работников здравоохранения перейти «от борьбы с эпидемиями к оздоровлению труда и быта населения».

Советская власть ставит приоритетной задачей санитарно-просветительскую работу. Был выдвинут лозунг «Налаживание народного здоровья, есть дело самих трудящихся». Для воплощения в жизнь этого лозунга стали читаться лекции по гигиене и санитарии на следующие темы: «Охрана здоровья в коммунистическом государ- стве»; «Народное здравоохранение».

Для того, чтобы санитарно-эпидемиологическая работа в регионе имела положительные результаты, необходимо было вести просветительскую деятельность среди населения. Самостоятельного подотдела санитарного просвещения в Губздраве не было. Санпросвет был влит в санитарно-эпидемиологический подотдел и руководил работой по санитарному просвещению в губернии $[15$, c. 41].

Санитарно-просветительская секция Губздрава печатала и рассылала по уездам Енисейской губернии агитационные листовки, брошюры, художественные плакаты и открытые письма о тифе и холере. Широкая агитационная компания против холеры, была открыта рядом статей в газетах, просвещающих население, что такое холера и методах борьбы с ней. Агитационная литература рассылалась по всей Енисейской губернии через почтовые учреждения, плакаты и листовки распространялись по школам через Наробраз. Для получения литературы была налажена связь с Наркомздравом, Сибздравом, Центропечатью, Пироговским обществом врачей в Москве. В уездных отделениях здравоохранения специальных средств на санитарное просвещение не имелось, как не было специально выделенных лиц санпросвета, поэтому говорить о планомерной работе не приходится. Для ознакомления широких слоев населения распространение получили передвижные выставки, просветительские лекции, спектакли на которых ставились пьесы, наглядно разъясняющие значение санитарно-гигиенических мероприятий. Проводились «Неделя чистоты», «Неделя водоснабжения». На заводах организовывались санитарные ячейки, формировались «штабы» и «комитеты» чистоты, к деятельности которых широко привлекались профсоюзы, комсомол, женотделы и другие общественные организации [1, л. 16-17].

В 1924 году санитарно-просветительской секцией были подготовлены выставки по школьной санитарии.

Статистика заразных заболеваний по Красноярскому округу

Таблица 3 [составлено по: 8, с. 102].

\begin{tabular}{|c|c|c|c|c|c|c|}
\hline \multirow{2}{*}{ Тиф брюшной } & 1925 г. & 1926 г. & 1927 г. & 1-я пол. 1927 г. & 1-я пол. 1928 г. \\
\cline { 2 - 7 } & Город & 145 & 200 & 131 & 37 & 42 \\
\hline \multirow{3}{*}{ Тиф сыпной } & Село & 271 & 744 & 1124 & 510 & 184 \\
& Город & 48 & 45 & 16 & 16 & 8 \\
\cline { 2 - 7 } & Село & 185 & 149 & 70 & 50 & 63 \\
\hline \multirow{2}{*}{ Тиф возвратный } & Город & 15 & 3 & 0 & 0 & 0 \\
\cline { 2 - 7 } & Село & 28 & 14 & 27 & 11 & 22 \\
\hline \multirow{2}{*}{ Малярия } & Город & 4666 & 1971 & 1016 & 728 & 544 \\
\cline { 2 - 7 } & Село & 7421 & 4838 & 2655 & 1131 & 1606 \\
\hline
\end{tabular}


У секции имелся склад наглядных пособий, который постоянно пополнялся. Заключались соглашения с редакциями местных газеты о выпуске санитарного листка, который должен идти как приложение к газете один раз в две недели, размещались статьи о профилактике заболеваний.

Между Губздравами шел постоянный обмен литературой. От Томского Губздрава были получены образцы изданной литературы. Для руководства санпросветом в окружном масштабе создавались центры, где разрабатывались и проверялись новые методы работы. Эти центры организовывали выставки, вели накопление местного материала.

К концу 1920-х годов определяются основные задачи санитарно-просветительской работы - она должна быть тесно связана с местными особенностями и интересами. Эти задачи осуществлялись через сеть домов санитарного просвета двух типов: для промышленных районов и для мелких городских поселений. В состав такого дома входил склад наглядных пособий, библиотека с читальней. Другой тип - это дома для сельской местности, где в основном проводились санитарно-гигиенические выставки.
Проводимая санитарно-просветительская деятельность приводила к сокращению заболеваемости. Однако в ее работе возникали трудности, которые в основном были связаны с отсутствием специалистов, наглядного материала, нехваткой материальных средств.

За первые десятилетия советской власти были предприняты серьезные шаги в плане формирования советской системы здравоохранения и улучшения эпидемиологической ситуации в Енисейской губернии. Получили организационное оформление органы управления советской медицины. Ликвидация последствий гражданской войны, улучшение санитарно-бытовых условий населения, повышение уровня жизни положительно сказалось на эпидемиологической ситуации в рассматриваемом регионе. Противоэпидемические меры привели к значительному сокращению ряда инфекционных заболеваний таких как тиф, малярия и к полному купированию эпидемии холеры. Постепенно ведущее значение в борьбе с инфекциями приобретает санитарно-просветительская деятельность. Хотя при этом эпидемическая ситуация в регионе на всем протяжении 1920-х годов продолжала оставаться сложной.

\section{ЛИТЕРАТУРА}

1. Государственный архив Красноярского края (ГАКК) Р.Ф. 136. Оп. 1. Д. 11.

2. ГАКК Р.Ф. 136. 0п. 1. Д. 55.

3. ГАКК Р.Ф. 136. ОП. 1.Д. 88.

4. ГАКК Р.Ф. 136. Оп. 1. Д. 116.

5. ГАККР.Ф. 136. ОП. 1. Д. 182.

6. ГАКК Р.Ф. 136. 0п. 1.Д. 277.

7. ГАКК. Р.Ф. 1224. Оп. 1. Д. 32.

8. Крылов И.И. Условия жизни горожан в Приенсейском регионе в 1921-1929 гг. Красноярск: Красноярский государственный торгово-экономический институт, 2010. $158 \mathrm{c}$.

9. От ревкомов к советам. Енисейский губернский отдел народного здравоохранения // Красноярский рабочий. 1920. 10 августа.

10. Отчет 0 2-м Ачинском уездном съезде Советов рабочих, крестьянских и красноармейских депутатов в городе Ачинске, 27 марта - 1 апреля 1921 года. Ачинск: Государственная типография, 1921. 120 c.

11. Познанский В.С. Социальные катаклизмы в Сибири: голод и эпидемии в 20 - 30-е годы XX века. Российская академия наук; Сибирское отделение; Институт истории. Новосибирск: издательство СО РАН, 2007. 307 с.

12. Полгода Советской власти в Енисейской губернии. Обзор деятельности советских учреждений с января по 1 августа 1920 г. Красноярск: Енисейское губернское государственное издательство, 1920. 227 с.

13. Становление советского здравоохранения в российской провинции в 1920-е годы // Проблемы социальной гигиены, здравоохранения и истории медицины. -2017 . - № 25 (1).

14. Статистические материалы по состоянию народного здравия и организации медицинской помощи в СССР за 1913-1923 гг., Издательство НКЗ РСФСР, Москва, 1926. 263 c.

15. Ханенко Б.И. Здравоохранение Красноярского края. Красноярск: Книжное издательство, 1991. 150 с.

16. Цилев К.А. Очерки становления советского здравоохранения в Сибири в период деятельности Сибревкома 1919-1925 гг. В кн. Деятельность Сиббюро ЦК РКП(б) и Сибревкома в 1919-1925 гг. Новосибирск, Т. 34. Кн. 1. 1960. 249 с.

17. Этапы развития органов и учреждений Роспотребнадзора на берегах Енисея. Красноярск: Офсет, 2017. 281 с. 